\title{
Proprioceptive Training on Dynamic Neuromuscular Control in Fencers: A Clinical Trial
}

\author{
Gabriela Souza de Vasconcelos, Anelize Cini, and Cláudia Silveira Lima
}

\begin{abstract}
Context: Fencing is a sport of agility, with a higher incidence of lower-limb injuries, of which the ankle sprain is the most prevalent. Injury prevention is very important to improve performance and decrease the withdrawal time of athletes. Proprioceptive training programs can be added to the training of athletes, since, in addition to easy application and low cost, proprioception has the function of stabilizing the ankle joint to prevent injuries. Objective: To verify the influence of a 12-week proprioceptive training program on dynamic neuromuscular control in fencing athletes. Design: The study was a clinical trial, and the athletes were allocated, for convenience, in the intervention group or in the control group. Setting: The study was developed in 4 stages (preintervention, intervention, postintervention, and follow-up of 3). The neuromuscular control during the star excursion balance test was evaluated. Participants: The participants were 19 fencing athletes (intervention group: 10, and control group: 9), aged 14-35 years, from a multisport club. Interventions: The athletes performed the proprioceptive training during 12 weeks, 3 times a week, with a duration of 30 minutes. Main Outcome Measures: Dynamic neuromuscular control. Results: The data and SE were considered for statistical analysis, submitted to the generalized estimates equations test with Bonferroni post hoc. The level of significance was .05. The distance reached in the star excursion balance test increased significantly in all 8 directions evaluated in the 2 legs of the intervention group. Conclusions: The proprioceptive training program was able to improve dynamic neuromuscular control in fencing athletes.
\end{abstract}

Keywords: proprioception, sports injuries, ankle injuries, prevention

Fencing is a sport of agility, characterized by, among others things, changes of direction and movements in acceleration and braking. ${ }^{1}$ Its practice requires dynamic neuromuscular control, which is the athlete's ability to maintain stability while moving quickly and reacting to changes in direction, attacks, and performing the defenses imposed by the activity. ${ }^{2}$

Due to its characteristics, approximately half of all injuries in fencers occur in the lower extremities, especially in the ankle and knee. ${ }^{3}$ This demonstrates that fencing injuries occur, as in other sports and in physically active individuals as well, where the ankle is among the sites most affected by acute and chronic injuries. ${ }^{4,5}$ More recently, Harmer ${ }^{6}$ accompanied fencing athletes for 5 years and found that the most frequent injury was ankle sprain.

Ankle sprain can lead to changes in the ankle neuromuscular and proprioceptive functions, as well as postural changes and decreased dynamic neuromuscular control, which has a negative effect on athletic performance, ${ }^{7}$ resulting in the removal of athletes from training and competitions and the further decrease in their performance..$^{8-10}$

Considering that, preventive programs, such as proprioceptive training, started to be implemented in clubs and sports organizations, due to its function of stabilizing the joint, avoiding the occurrence of sprains or the recurrence of these injuries. ${ }^{1-14}$

The effects of proprioceptive training on dynamic neuromuscular control were investigated in volleyball athletes for a period of 4 weeks ${ }^{15}$ and in soccer athletes for 6 weeks, ${ }^{16}$ and both studies identified that there was a significant increase in distance achieved in the star excursion balance test (SEBT) by the intervention group

The authors are with the Department of Physical Education, Physical Therapy and Dance, Universidade Federal do Rio Grande do Sul, Porto Alegre, RS, Brazil. de Vasconcelos (vasconcelosgs@gmail.com) is corresponding author.
(IG) when compared with the control group (CG). Other studies also show that proprioceptive training significantly improved the distance achieved in SEBT in physically active individuals for 4 weeks. ${ }^{17,18}$ However, O'Driscoll et $\mathrm{al}^{19}$ found that a 6 -week proprioceptive training program in rugby athletes did not alter dynamic neuromuscular control. This leads to the consideration that the characteristic of the sports modality can interfere in the possible gains of a proprioceptive training program.

However, no studies aiming at the proposed investigation on proprioceptive training and its influence on dynamic neuromuscular control in fencers have been found. The few studies carried out with fencers evaluate the performance improvement, ${ }^{20-23}$ the kinematics of specific gestures, ${ }^{24,25}$ and the influence of shoes and surfaces during the practice of this sport. ${ }^{26}$

Therefore, the objective of the present study was to verify the influence of a 12-week proprioceptive training program on dynamic neuromuscular control in fencing athletes. The study hypothesis was that participants who receive the proprioceptive training program would show significant improvement in the SEBT range.

\section{Methods}

\section{Study Design}

The present study is a clinical trial. This study was submitted and approved by the Ethics Committee of the Federal University of Rio Grande do Sul under the opinion of number 1,455,237 registered in the Clinical Trial under number NCT02739308.

\section{Participants}

The population was the fencing team, composed of 22 athletes (precadets [from 14 to $15 \mathrm{y}$ ], cadets [up to $17 \mathrm{y}$ ], juveniles [up to 
$20 \mathrm{y}$, and free adults) from a multisport club, of both sexes. The inclusion criteria were practicing fencing for at least 1 year and being 14-35 years old. The exclusion criteria were being under physiotherapeutic treatment or preventive training for injuries, having injuries to the lower limbs that compromised the performance of the tests, and missing 3 consecutive or 5 alternate sessions of the training program. All athletes who met the criteria and agreed to participate were included in the study, totaling 19 fencers, divided into 2 groups (IG and CG).

Before participating, the athletes were invited to read and to sign the consent form. Athletes under the age of 18 had their consent form signed by their guardians.

\section{Procedures}

The study was developed in 4 stages: (1) preintervention, (2) intervention, (3) postintervention, and (4) 3-month follow-up.

The athletes were allocated, for convenience, in the IG or in the CG. The established form of allocation was that the first 10 athletes evaluated would go to the IG, and the others would go to the CG. On the same day, they performed the evaluation of the dynamic neuromuscular control, related to the preintervention stage. A week after the test, the intervention stage started, which consisted of a 12-week proprioceptive training program.

The SEBT was used to evaluate the dynamic neuromuscular control of the ankles. It is composed of 8 lines in different directions (anterior, anteromedial, medial, posteromedial, posterior, posterolateral, lateral, and anterolateral; with angles of $45^{\circ}$ between each direction and each line with $120 \mathrm{~cm}$ ). The test requires the participant to maintain balance in unipodal support, while the contralateral leg attempts to reach as far as possible in a predetermined direction. The test was performed bilaterally, barefoot, and with hands held at the waist. The distance was measured in centimeters, and the average of 3 replicates in each direction was used in the study. ${ }^{27}$

The intervention consisted of the application of a proprioceptive training program for fencing athletes selected for the IG. This program was adapted from the proposed training program for volleyball athletes by Hupperets et al, ${ }^{28}$ composed of 14 exercises and divided into 4 categories (without material, with specific material of the sport, with proprioceptive disc/proprioceptive disc and specific material of the sport, and with a weekly intensity progression).

The training program (Table 1) was developed for 12 weeks, 3 times a week and was applied during athletes' warm-up, in a 30-minute session. Each week, 3 exercises of the 14 adapted to the fencing athletes were chosen, being, preferably, one from each category. The categories presented exercises with different levels of difficulty, and the changes in the exercises could occur by the different levels proposed or by the complexity of the exercise by changing the category. The training program was applied by the same researcher over the 12 weeks.

\section{Statistical Analysis}

Statistical analysis was performed using SPSS $^{\circledR}$ (version 18.0; IBM Corp, Armonk, NY). The data were presented in mean and SE and submitted to the Shapiro-Wilk test to verify their normality. The independent $t$ test was used to compare the characterization variables of the sample. For the analysis of the variables in the different moments (pre, post, and $3 \mathrm{mo}$ ) and between the groups (intervention and control), the generalized estimates equations test with Bonferroni post hoc was applied. The level of significance was set at .05 .

\section{Results}

Among the fencing athletes invited to participate in the study, 10 were allocated in the IG and 9 in the CG. In both groups, losses and exclusions occurred during the study, according to Figure 1.

The characterization of the sample, related to sex, age, height, and mass, is presented in Table 2.

The data obtained through the SEBT showed that there was a significant increase in the distance reached in all 8 directions evaluated, both in the front leg and in the back leg of the IG (Table 3).

Regarding the CG, the directions evaluated, in most moments, did not present significant difference in the distances reached by the front leg and the hind leg. However, some exceptions were observed in the anterior, posterior, medial, and anteromedial anterior leg and in the anterior, anterolateral, lateral, medial, and anteromedial directions (Table 3).

\section{Discussion}

This study verified the influence of a 12-week proprioceptive training program on dynamic neuromuscular control in fencing athletes. The study hypothesis that there would be an improvement in dynamic neuromuscular control was confirmed by the results.

The SEBT scores for the evaluation of dynamic neuromuscular control in fencers increased significantly in all directions, both in the front leg and in the hind leg in the IG at the 4 assessment moments. In contrast, the CG presented inconsistencies in its results, with no significant difference in the majority of the evaluated moments.

The difference observed in the IG can be due to the stimulus of the proprioceptive training added to the technical training of the athletes, who, together, promoted a challenge to the multidirectional stability and provided a significant increase in all directions. The CG was influenced only by technical training, which seemed to challenge only the directions in which the demand of eversors was superior to the others, especially in the front leg.

The improvement of dynamic neuromuscular control promoted by proprioceptive training is a relevant result, since this variable has a significant effect on athletic performance, ${ }^{7}$ especially in athletes who are frequently exposed to injuries. The literature also emphasizes that the improvement in distance achieved in SEBT is a relevant factor in the prevention of ankle sprains. ${ }^{27,29}$ This is probably due to the fact that the SEBT evaluates the different ankle muscle groups, since each direction presents a different muscular demand. It is possible to identify a greater demand for the plantar flexor muscles, in the anterior direction, in the lateral direction for the inverters, in the posterior direction for the dorsiflexors, in the medial direction for the eversors, ${ }^{30}$ and in the other directions, a combination of these muscles to improve dynamic neuromuscular control.

Other studies with proprioceptive training ${ }^{15-18}$ also obtained satisfactory results at the distances reached in the SEBT. 
Table 1 Exercises and Variations of the Different Categories of the Proprioceptive Training Program

\begin{tabular}{|c|c|c|c|}
\hline Without material & With foil & With proprioceptive disc & $\begin{array}{l}\text { With foil and proprioceptive } \\
\text { disc }\end{array}$ \\
\hline $\begin{array}{l}\text { Exercise } 1 \\
\text { Stand on } 1 \text { leg, with the knee of } \\
\text { the opposite leg flexed, hold } \\
\text { for } 5 \mathrm{~s} \text {, and repeat } 10 \times \text { for each } \\
\text { leg }(1,2,3 \text {, and } 4) .\end{array}$ & $\begin{array}{l}\text { Exercise } 3 \\
\text { In pairs, stand on } 1 \text { leg and, with the } \\
\text { knee of the opposite leg bent, simu- } \\
\text { late fencing gestures } 5 \times \text { with each } \\
\text { hand, and repeat } 10 \times \text { for each } \\
\text { leg }(1 \text { and } 2) \text {. }\end{array}$ & $\begin{array}{l}\text { Exercise } 5 \\
\text { Stand on the disc in unipedal support, } \\
\text { with the knee of the opposite leg } \\
\text { flexed, hold for } 30 \mathrm{~s} \text {, and repeat } 2 \times \text { for } \\
\text { each leg }(1,2,3 \text {, and } 4) \text {. }\end{array}$ & $\begin{array}{l}\text { Exercise } 7 \\
\text { In pairs, one athlete stands on the disc } \\
\text { in bipodal support and other stands } \\
\text { on the floor, both performing } 10 \times \\
\text { fencing gestures for each hand while } \\
\text { maintaining balance. Athletes must } \\
\text { repeat } 2 \times \text { in each position. }\end{array}$ \\
\hline $\begin{array}{l}\text { Exercise } 2 \\
\text { Stand on } 1 \text { leg, with the knee } \\
\text { and hip of the opposite leg } \\
\text { flexed, hold for } 5 \mathrm{~s} \text {, and repeat } \\
10 \times \text { for each leg }(1,2,3 \text {, and } 4) \text {. }\end{array}$ & $\begin{array}{l}\text { Exercise } 4 \\
\text { In pairs, stand on 1-legged support } \\
\text { and with the opposite knee and hip } \\
\text { flexed, simulate fencing gestures } 5 \times \\
\text { with each hand, and repeat } 10 \times \text { for } \\
\text { each leg ( } 1 \text { and } 2) \text {. }\end{array}$ & $\begin{array}{l}\text { Exercise } 6 \\
\text { Stand on the disc in unipedal support, } \\
\text { with knee and hip of the opposite leg } \\
\text { flexed, hold for } 30 \mathrm{~s} \text {, and repeat } 2 \times \text { for } \\
\text { each leg }(1,2,3 \text {, and } 4) \text {. }\end{array}$ & $\begin{array}{l}\text { Exercise } 8 \\
\text { In pairs, one athlete stands on the disc } \\
\text { in unipedal support, with the knee of } \\
\text { the opposite leg flexed, while the } \\
\text { other athlete is in the same position } \\
\text { on the floor. Both perform } 10 x \\
\text { fencing gestures with each hand and } \\
\text { change the leg. They should repeat } \\
2 \times \text { in each leg and } 2 \times \text { in each position } \\
(1 \text { and } 2) \text {. }\end{array}$ \\
\hline \multirow{3}{*}{\multicolumn{2}{|c|}{$\begin{array}{l}\text { Variations: } \\
\text { 1. The extended support leg. } \\
\text { 2. The flexed support leg. } \\
3 \text { The extended support leg and eyes closed. } \\
\text { 4. The bent support leg and eyes closed. } \\
\text { 5. Both flexed legs and fencing attack technique with high-foil position. } \\
\text { 6. The flexed support leg and the extended back, and the technique of } \\
\text { fencing attack with high-foil position. } \\
\text { 7. Both flexed legs and fencing attack technique with low-foil position. } \\
\text { 8. The flexed support leg and the extended back, and the fencing attack } \\
\text { technique with low-foil position. }\end{array}$}} & $\begin{array}{l}\text { Exercise } 9 \\
\text { Stand one foot on the disc and the } \\
\text { other on the ground. Perform the } \\
\text { upward movement on the disc, with } \\
\text { hip and knee flexion of the leg that } \\
\text { was on the ground. Repeat } 10 \times \text { for } \\
\text { each leg. }\end{array}$ & $\begin{array}{l}\text { Exercise } 10 \\
\text { In pairs, one athlete stands on the disc } \\
\text { in unipedal support, with the opposite } \\
\text { knee and hip flexed, while the other } \\
\text { athlete is in the same position on the } \\
\text { floor. Both perform } 10 x \text { fencing } \\
\text { gestures with each hand and change } \\
\text { the leg. They should repeat } 2 \times \text { for } \\
\text { each leg and } 2 \times \text { in each position } \\
(1 \text { and } 2) \text {. }\end{array}$ \\
\hline & & $\begin{array}{l}\text { Exercise } 11 \\
\text { Stand on the disc in bipodal support } \\
\text { and perform } 10 \text { squats while main- } \\
\text { taining balance, and repeat } 2 \times \text {. }\end{array}$ & $\begin{array}{l}\text { Exercise } 12 \\
\text { In pairs, an athlete moves sideways } \\
\text { with the foot up, simulating the } 10 \times \\
\text { lunge; and the other athlete starts off } \\
\text { with both feet on the puck and re- } \\
\text { treats outward, simulating the } 10 \times \\
\text { offense defense. Athletes must repeat } \\
2 \times \text { in each position }(5,6,7 \text {, and } 8) \text {. }\end{array}$ \\
\hline & & $\begin{array}{l}\text { Exercise } 13 \\
\text { In forward position, with the front leg } \\
\text { over the disc, perform } 10 \text { squats } \\
\text { while maintaining balance, and } \\
\text { repeat } 2 \times \text { for each leg. }\end{array}$ & $\begin{array}{l}\text { Exercise } 14 \\
\text { In pairs, an athlete advances from the } \\
\text { front with the foot upward and per- } \\
\text { forms an attack gesture, simulating } \\
\text { the } 10 \mathrm{x} \text { lunge; and the other athlete } \\
\text { starts with both feet on the puck and } \\
\text { retreats outward, simulating the } 10 \times \\
\text { offense defense. Athletes must repeat } \\
2 \times \text { in each position }(5,6,7 \text {, and } 8) \text {. }\end{array}$ \\
\hline
\end{tabular}

Source: Hupperets et al. ${ }^{28}$

McKeon et al $^{18}$ applied 4 weeks of proprioceptive training with individuals with ankle instability and obtained a significant increase in the reach of 2 (posteromedial and posterolateral) of the 3 directions evaluated. Hale et al $^{17}$ also evaluated 4 weeks of proprioceptive training with healthy subjects and identified that the IG reached significantly greater distances than the CG in the anterior and posteromedial directions, but without significant differences in the posterolateral direction.

The posteromedial direction was the only one that presented a significant increase in the distance reached in all mentioned studies, including in the present study. This information suggests that the direction with the greatest difficulty of stabilization ${ }^{30}$ is the most favored by the effects of the proprioceptive training, which may be the factor that relates the good performance in the SEBT to the prevention of ankle injuries.

Among the studies cited, Peres et $\mathrm{al}^{15}$ and Filipa et $\mathrm{al}^{16}$ used SEBT as an evaluation method in soccer and volleyball athletes, respectively. Both studies applied the proprioception training and identified that the IG reached greater distances in the posterolateral and posteromedial directions compared with the 


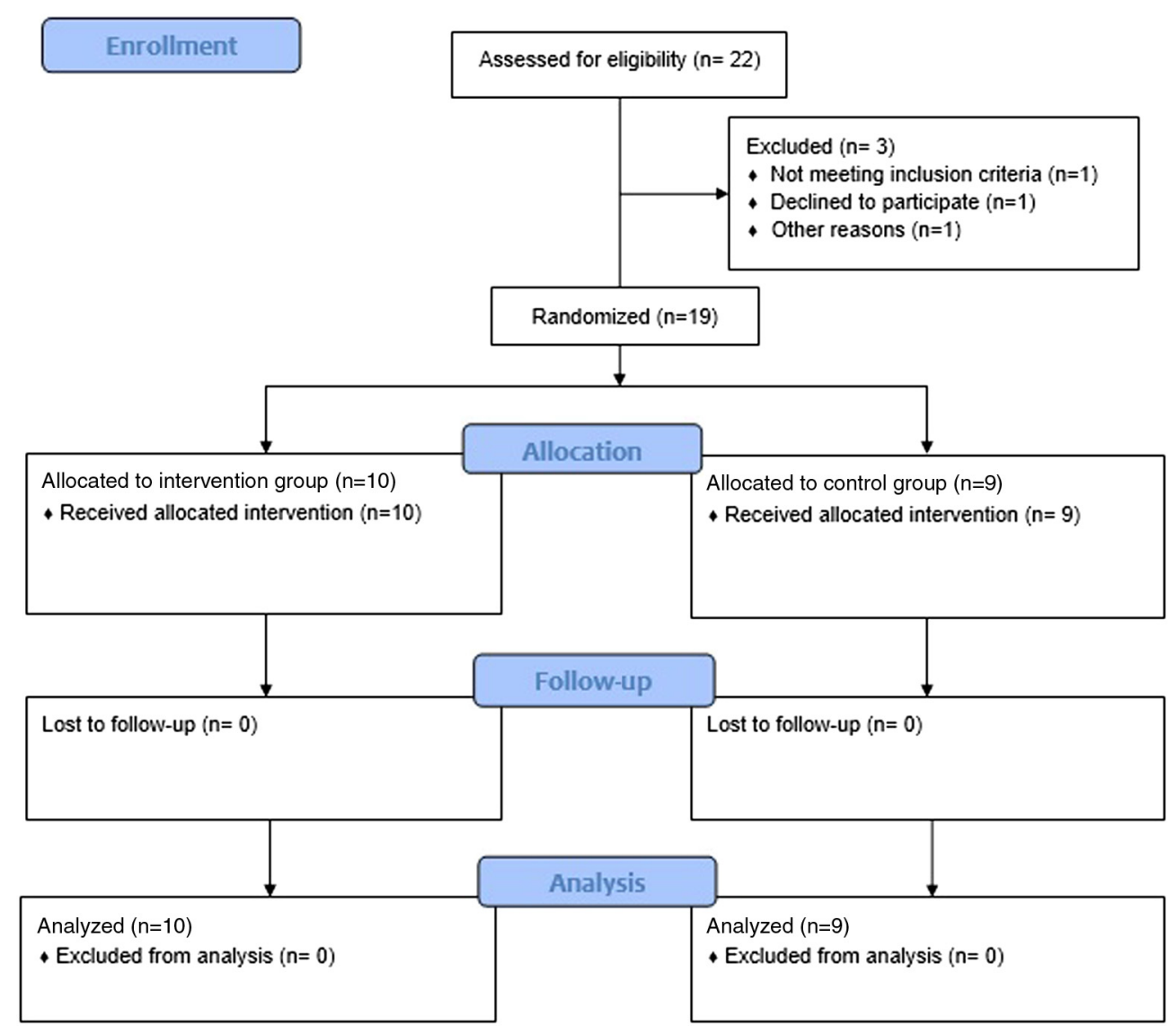

Figure 1 - Flowchart of the participants during each moment of the study.

Table 2 Mean and SD of the Sample Characterization Variables

\begin{tabular}{|c|c|c|c|}
\hline & Intervention group $(n=10)$ & Control group $(n=9)$ & $\boldsymbol{P}$ \\
\hline \multicolumn{4}{|l|}{ Sex } \\
\hline Male & 6 & 7 & \\
\hline Female & 4 & 2 & \\
\hline Age, y & $16.80(2.34)$ & $24.00(6.65)$ & $.01 *$ \\
\hline Stature, $\mathrm{m}$ & $1.74(0.10)$ & $1.76(0.04)$ & .64 \\
\hline Mass, kg & $69.04(11.37)$ & $70.22(10.55)$ & .81 \\
\hline \multicolumn{4}{|c|}{ Tempo de treino, $y$} \\
\hline $4-5$ & $30 \%$ & $11.1 \%$ & \\
\hline $6-7$ & $20 \%$ & $0 \%$ & \\
\hline$>8$ & $50 \%$ & $88,8 \%$ & \\
\hline
\end{tabular}

$* P \leq .05$.

CG. This information corroborates with the results of the present study and reinforces the fact that the proprioceptive training stimulates the multidirectional stability of the joint.

Because the results of the studies mentioned above demonstrate significant differences only in some directions, it is suggested that the proprioceptive training be performed for a time equal to or greater than 12 weeks, so that a significant increase occurs in all 8 directions evaluated, as observed in this study.
Among the limitations of the study, it was not possible to randomize athletes or the number of athletes, and the data obtained by the study cannot be extrapolated to other sports, because the characteristics of fencing are very peculiar.

\section{Conclusions}

A 12-week proprioceptive training program is capable of improving dynamic neuromuscular control in fencing athletes. 


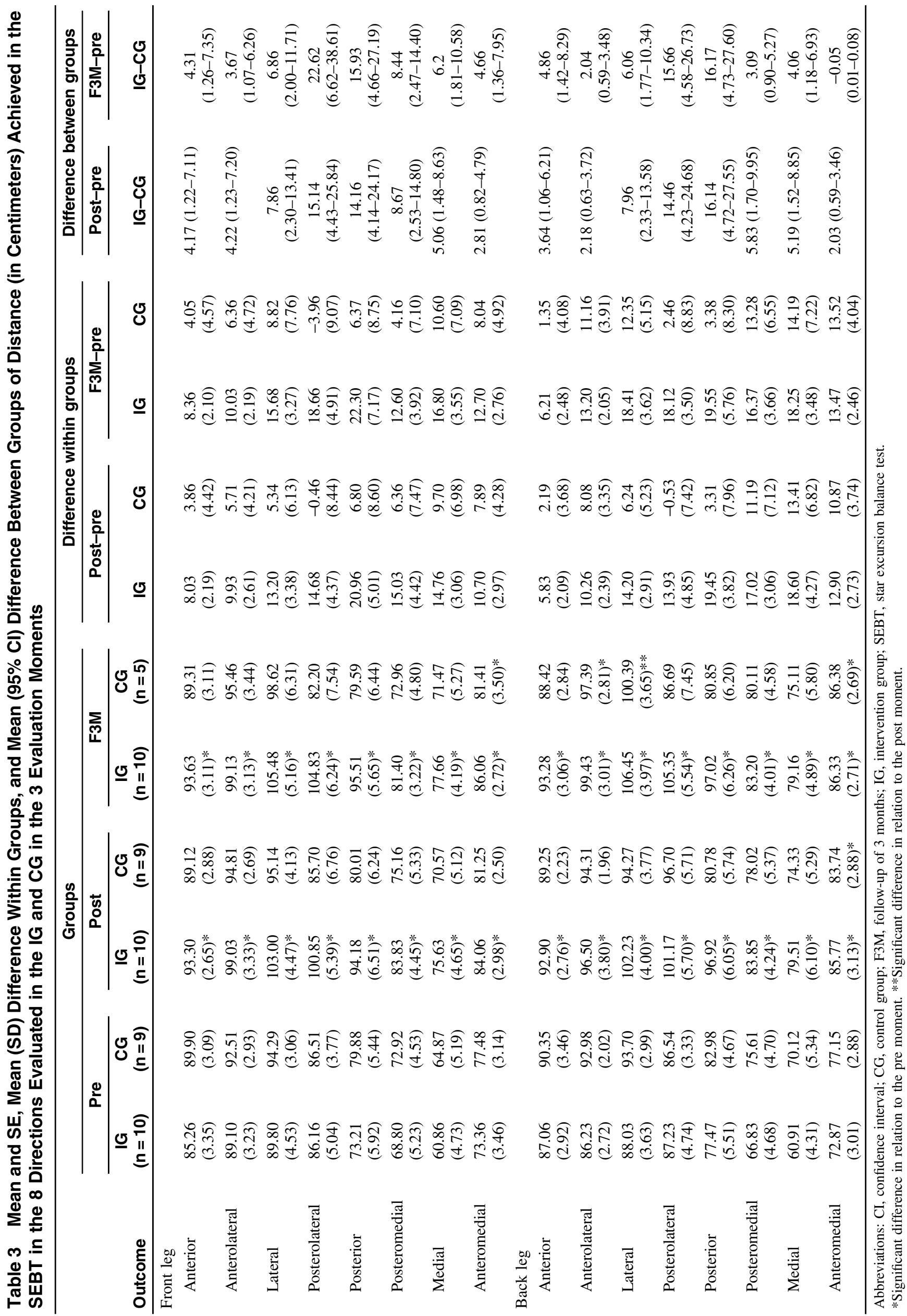




\section{Acknowledgments}

The authors declare that they have no competing interests. None of the authors received any funding for this study.

\section{References}

1. Sheppard JM, Young WB. Agility literature review: classifications, training and testing. J Sport Sci. 2006;24:919-932. doi:10.1080/ 02640410500457109

2. Winter DA, Patla AE, Frank JS. Assessment of balance control in humans. Med Prog Technol. 1990;16:31-51. PubMed ID: 2138696

3. Zemper ED, Harmer PA. Fencing. In: Caine DJ, Caine CG, Lindner KJ, eds., Epidemiology of Sports Injuries. Champaign, IL: Human Kinetics; 1996:186-195.

4. Fong DT, Hong Y, Chan LK, Yung PS, Chan KM. A systematic review on ankle injury and ankle sprain in sports. Sports Med. 2007;37:73-94. PubMed ID: 17190537 doi:10.2165/00007256200737010-00006

5. Hootman JM, Dick R, Agel J. Epidemiology of collegiate injuries for 15 sports: summary and recommendations for injury prevention initiatives. J Athl Train. 2007;42(2):311-319. PubMed ID: 17710181

6. Harmer PA. Getting to the point: injury patterns and medical care in competitive fencing. Curr Sports Med Rep. 2008;7(5):303-307. PubMed ID: 18772692 doi:10.1249/JSR.0b013e318187083b

7. Hrysomallis C. Balance ability and athletic performance. Sports Med. 2011;41:221-232. PubMed ID: 21395364 doi:10.2165/11538560000000000-00000

8. Arnold BL, De la Motte S, Linens S, Ross SE. Ankle instability is associated with balance impairments: a meta-analysis. Med Sci Sports Exerc. 2009;41:1048-1062. PubMed ID: 19346982 doi:10.1249/ MSS.0b013e318192d044

9. McKeon PO, Hertel J. Systematic review of postural control and lateral ankle instability, part I: can deficits be detected with instrumented testing. J Athl Train. 2008;43(3):293-304. PubMed ID: 18523566 doi:10.4085/1062-6050-43.3.293

10. Zech A, Hubscher M, Vogt L, Banzer W, Hansel F, Pfeifer K. Neuromuscular training for rehabilitation of sports injuries: a systematic review. Med Sci Sports Exerc. 2009;41:1831-1841. PubMed ID: 19727032 doi:10.1249/MSS.0b013e3181a3cf0d

11. Harmer P. Sports medicine Q \& A. Am Fence. 2007;57(4):23.

12. McGuine TA, Keene JS. The effect of a balance training program on the risk of ankle sprains in high school athletes. Am J Sports Med. 2006;34(7):1103-1111. PubMed ID: 16476915 doi:10.1177/ 0363546505284191

13. McHugh MP, Tyler TF, Mirabella MR, Mullaney MJ, Nicholas SJ. The effectiveness of a balance training intervention in reducing the incidence of noncontact ankle sprains in high school football players. Am J Sports Med. 2007;35:1289-1294. PubMed ID: 17395956 doi:10.1177/0363546507300059

14. Mohammadi F. Comparison of 3 preventive methods to reduce the recurrence of ankle inversion sprains in male soccer players. Am J Sports Med. 2007;35(6):922-926. doi:10.1177/0363546507299259

15. Peres MM, Cechini L, Pacheco I, Pacheco AM. Efeitos do treinamento proprioceptivo na estabilidade do tornozelo em atletas de voleibol. Rev Bras Med Esporte. 2014;20(2):146-150. doi:10. 1590/1517-86922014200202046
16. Filipa A, Byrnes R, Paterno M, Myer GD, Hewett T. Neuromuscular training improves performance on the star excursion balance test in young female athlete. J Orthop Sports Phys Ther. 2010;40(9):551558. PubMed ID: 20710094 doi:10.2519/jospt.2010.3325

17. Hale S, Fergus A, Axmacher R, Kiser K. Bilateral improvements in lower extremity function after unilateral balance training in individuals with chronic ankle instability. J Athl Train. 2014;49:181-191. PubMed ID: 24568231 doi:10.4085/1062-6050-49.2.06

18. McKeon PO, Ingersoll CD, Kerrigan DC, Saliba E, Bennett BC, Hertel J. Balance training improves function and postural control in those with chronic ankle instability. Med Sci Sports Exerc. 2008;40(10):1810-1819. PubMed ID: 18799992 doi:10.1249/MSS. 0b013e31817e0f92

19. O’Driscoll J, Kerin F, Delahunt E. Effect of a 6-week dynamic neuromuscular training programme on ankle joint function: a case report. Sports Med Arthrosc Rehabil Ther Technol. 2011;3:13. doi:10.1186/1758-2555-3-13

20. Gutiérrez-Dávila M, Rojas FJ, Caletti M, Antonio R, Navarro E. Effect of target change during the simple attack in fencing. J Sport Sci. 2013;31:1100-1107. doi:10.1080/02640414.2013.770908

21. Gutiérrez-Dávila M, Zingsem C, Gutiérrez-Cruz C, Giles FJ, Rojas FJ. Effect of uncertainty during the lunge in fencing. J Sports Sci Med. 2014;13:66-77.

22. Poulis J, Chatzis S, Christopoulou K, Tsolakis C. Isokinetic strength during knee flexion and extension in elite fencers. Percept Mot Skills. 2009;108:949-961. PubMed ID: 19725328 doi:10.2466/pms.108.3. 949-961

23. Redondo JC, Alonso CJ, Sedano S, de Benito AM. Effects of a 12week strength training program on experimented fencers' movement time. J Strength Cond Res. 2014;28(12):3375-3384. PubMed ID: 24942170 doi:10.1519/JSC.0000000000000581

24. Bottoms L, Greenhalgh A, Sinclair J. Kinematic determinants of weapon velocity during the fencing lunge in experienced épée fencers. Acta Bioeng Biomech. 2013;15(4):109-113.

25. Gholipour M, Tabrizi A, Farahmand F. Kinematics analysis of lunge fencing using stereophotogrametry. World J Sport Sci. 2008;1(1): 32-37.

26. Greenhalgh A, Bottoms L, Sinclair J. Influence of surface on impact shock experienced during a fencing lunge. J Appl Biomech. 2012;29(4):463-467. PubMed ID: 22923353 doi:10.1123/jab.29. 4.463

27. Gribble PA, Kelly SE, Refshauge KM, Hiller CE. Interrater reliability of the star excursion balance test. J Athl Train. 2013;48(5):621-626. PubMed ID: 24067151 doi:10.4085/1062-6050-48.3.03

28. Hupperets MD, Verhagen EA, van Mechelen W. Effect of unsupervised home based proprioceptive training on recurrences of ankle sprain: randomised controlled trial. BMJ. 2009;339:b2684. PubMed ID: 19589822 doi:10.1136/bmj.b2684

29. Bastien M, Moffet H, Bouyer LJ, Perron M, Hébert LJ, Leblond J. Alteration in global motor strategy following lateral ankle sprain. BMC Musculoskelet Disord. 2014;15:436. PubMed ID: 25515309 doi:10.1186/1471-2474-15-436

30. Gabriner ML, Houston MN, Kirby JL, Hoch MC. Contributing factors to star excursion balance test performance in individuals with chronic ankle instability. Gait Posture. 2015;41:912-916. PubMed ID: 25845724 doi:10.1016/j.gaitpost.2015.03.013 